\title{
Management of changes in companies of the agro-industrial complex: implementation of high technologies
}

\author{
Ekaterina Vinogradova, and Anna Galimova \\ Ural State University of Economics, Department of Information technology and statistics, 8 Marta St., \\ 62, 620219 Ekaterinburg, Russia
}

\begin{abstract}
Digitalization is the most powerful tool for increasing the efficiency of agricultural enterprises. A computerized microclimate control system, the use of chip tags for animals and scanners to read information from these tags and enter data into the system, the use of flow meters, equipping machines with GPS sensors, the implementation of precision farming, space survey can improve the quality of production and monitoring, as well as neutralize the negative influence of the external environment on production efficiency. The ability to digitize agrotechnological processes based on the creation of expert systems carrying out multiple factor analysis based on complex mathematical models. Monitoring and accounting of certain factors influence is performed on these platforms based on machine learning and a neural network. The introduction of high technologies should be carried out in close connection with the business processes reengineering, management of ongoing changes to achieve the maximum effect from the high technologies implementation.
\end{abstract}

\section{Introduction}

Currently, the main factors influencing the direction and intensity of organizational changes are the development of the market, technical progress and changes in the requirements for working conditions. The market makes new demands on the manufacturer due to the saturation of demand with consumer goods and the reduction in the life cycle of high-tech products. In this regard, companies are forced to expand the product range, strive to develop an innovative market and an increase production flexibility. Organizations can no longer cope with the increased needs of consumers without implementing high technologies into the production process.

Manufacturing of high quality products that can satisfy customer requirements is a complex process depended on many factors. In this regard, it is important for the manager to know in advance about all possible problems and be able to mitigate their negative impact in time. Economic planning is one of the most significant elements of the organization and management of production, which makes it possible to cover all areas of activity in their relationship with each other, as well as with external and internal factors. 
A modern enterprise is a complex of interrelated factors of production, united by a technological process. In accordance with the marginalist theory, the classification of production factors includes labor (labor resources), land (natural resources), capital (financial resources), entrepreneurial abilities. Within the framework of the economic theory of post-industrial society, information resources are added to the factors of production, and then innovations, as an integral part of effective production. Under the influence of scientific and technological progress, the development of innovations plays a significant role in improving the product quality and the enterprise competitiveness.

This approach will enable to control over the dynamics of all activities of the enterprise in their relationship, which will ensure the coordinated and targeted work of individual subsystems. The main tasks of implementing high technologies in the agro-industrial complex are the maximum efficient use of resources, primarily land, and control over their use, large farms' management, and difficult climatic conditions.

\section{Materials and methods}

The specificity of the high-tech measures implementation in the agro-industrial complex is due to a complex assessment of its cost in the formation of planning documents. This is due to the following factors:

- a wide range of products created at different stages of the life cycle during the activities implementation;

- the use of initial data with various degrees of reliability and details to estimate the activity cost;

- a large number of factors affecting the cost of product creation [5];

- an actual duration of implementation may vary significantly from the planned one;

- the probability of the desired result's non-availability from the implementation.

The exclusive introduction of high technologies into the practice of agro-industrial enterprises does not ensure high efficiency of the company even in case of significant implementation costs [6]. This is due to recurring problems in many organizations, which are characteristic of the insufficient preparation of the management process for innovation implementation. Potential problems include:

1. Absence or formal implementation of the preparatory stage. Some owners or managers rely on intuitive desires and advertisements in the selection of implemented innovations. At the same time, manufacturers of high technologies are not sufficiently aware of the current problems of the agro-industrial complex [8]. Evidently, they are based on the experience of Western countries and do not correspond to the modern realities of Russian enterprises. As a result, the selected high technologies are not effective enough. For example, at present, the priority is the problem of inaccurate data from the fields, lack of technology, rather than heterogeneity of soil fertility.

2. Limitation of the implementation period. Based on the results of the implementation, agro-industrial enterprises pay tribute to innovations, avoiding verification and serious analysis based of the implementation results. The main achievement for them was the fact of implementation without further monitoring and improvement of changes [4]. Cosequently, significant errors are unnoticed, leading to a decrease in the implementation efficiency.

3. Inconsistency between the desired high-tech impact and the company's strategic objectives can cause irreparable damage to the enterprise due the following reasons:

- this difference causes inconsistency in actions of the structural divisions' heads;

- there may be a lack of ability to complete orders, in particular those of strategic importance; 
- in connection with the resource allocation, not in accordance with strategic objectives, but according to the subjective opinions of the enterprise management, the main task of the employees is to fight for financial resources, and not to achieve the goals set [7].

Many companies do not have an approved list of strategic goals. In this regard, in such enterprises there is no certain system of resource allocation, subjective assessments of managers are the only factor influencing the formation of priority [10]. Nevertheless, a carefully formulated strategy in many cases does not justify the allocation of financial resources.

This factor in the future may be viewed as a reason for losing the company's competitive advantage, as well as its market share.

4. The main goal of the implementation is to reduce costs at the expense of creating value for the company's owners and customers. Enterprises aim at reducing costs across business units by leveraging resources efficiently [3]. This approach does not lead to an increase in the product quality and the development of the customer base and, as a result, it is not concerned with the creation of additional value for the customers.

5.Employees are not ready for changes. Managers conduct lectures formally on the need to introduce high technologies, and it does not lead to the staff's interest in the upcoming changes [1].

\section{Results and discussion}

The introduction of high technology refers to organizational changes and cannot be a onetime action. It should be carried out gradually, and then constantly support the changes made, and improve them. The authors suggest to use the PDCA cycle to improve the activities of the agro-industrial complex by implementing high technologies.

1. A thorough analysis of the actual state of the company's internal processes and changes in the external environment (political changes, instability of the situation in the national market, the emergence of new proposals in the field of enterprise activities and others) before choosing the technologies necessary for implementation will enable us to assess the improvement potential and analyze the implementation efficiency. The preliminary analysis will create a basis for assessing the improvement potential and conducting the implementation efficiency analysis.

An agro-industrial enterprise at the stage of concluding a contract should have the opportunity to study comprehensively the cost and time indicators of high technologies in order to maximize the leveling of information asymmetry and determine the correct price for the introduced type of high-tech products.

The cost of a high-tech product is influenced by several factors. For a high-tech enterprise, an important role is played by the amount of costs incurred and the expected profitability [2]. But due to the product uniqueness for the agro-industrial complex, the consumer value, which is the benefit to the buyer, is crucial in determining the value. Within the framework of this study, the use of the following groups of indicators is proposed for assessing consumer value:

- a set of basic characteristics of high-tech products planned for the use in the agroindustrial complex;

- cost indicators;

- product implementation effect.

The cost indicators, which are the basis for determining the consumer value of high-tech products, include the cost of implementing individual works and the entire life cycle of a prototype, the unit cost of the main characteristics of the sample, the effect of use [9]. The definition of customer value is based on a comparison of the listed indicators of the activity under consideration and the counterpart activity. 
2. Approbation of a high-tech sample with a decomposition of the project into manageable elements of work, for which it is easy to determine costs and build performance schedules, study the results at the intermediate stages.

3. Control and rigorous analysis of the intermediate results obtained for large-scale improvement transfers. Monitoring of exceptional cases related to external causes is carried out. In the event of errors connected with process imperfection, the second stage is returned and corrected until a satisfactory result is obtained.

4. Large-scale introduction of high technologies, documentation and regular control. Repeating this cycle to debug and improve the work process.

To prepare employees for high-tech implementations, it is necessary to go through the stages of the K. Levin change model, based on the formula "The higher the social value of the group standard, the greater will be the resistance of an individual group member to move away from the level of this group standard." To introduce high technologies, managers of the agro-industrial complex companies need to implement consistently the following steps with the choice of some proposed methods (depending on the situation, type of high-tech products, policy of the company owner and managers):

1. defrosting (loosening of group standards if necessary):

- method of bridge burning (artificial crisis creation);

- command (order) method;

- MBO (management by objectives, enabling selection);

- argumentation;

- destabilization and search for ways of development;

- learning to accept changes;

- company's reorganization;

2. change (transition):

- method "boil a frog" (invisible implementation of changes);

- "take on weakly" (challenge the employee in order to motivate him);

- training and coaching;

- "first step" method (positive emotional perception of the first stage of changes);

- enrichment of job responsibilities (to enable the employee to feel his importance and significance in the process of change);

- "move - freeze" (changes in small parts with intermediate stabilization).

3. freezing (fixing at a new level):

- method of bridge burning (no way back),

- flow of facts (constant reminder of the success of change),

- "gold handcuffs" (favorable offers to key employees),

- money motivation

- socialization (attracting informal leaders to the side of change).

Involving employees in the change management process will lead to additional motivation and an increased desire to implement high technology, which will have a positive impact on the result.

\section{Conclusions}

Thus, there are some problems that enterprises face in the process of implementing high technologies, as well as controlling the plans implementation. But, nevertheless, the authors show possible ways of solving or minimizing these problems. The high-quality implementation of high technologies is currently necessary for the agro-industrial complex. Managers must pass the company through a series of the successive stages, without diminishing the significance of any of these stages. Then it will be possible to avoid the 
thoughtless implementation of foreign developments and the digitalization discrediting as a tool for solving production problems. Having been adapted to modern realities through the high technologies implementation, the Russian agricultural complex will be actively involved in developing precision farming technologies and a number of other technologies for translating data into a digital reality.

\section{References}

1. V. Botrić, L. Bozić, Int. J. Innov. Technol. Manage. 4, 1850033 (2018)

2. H. Dzwigol, S. Shcherbak, M. Semikina, O. Vinichenko, V. Vasiuta, Acad. Strateg. Manag. J. 18 (1), 6 (2019)

3. O. V.Glinkina, S.A.Ganina, A. V. Maslennikova, T. A. Solostina, M. Viktorovna Soloveva, IJM. 3(19), 461 (2020)

4. N. I. Kuznetsov, N. V. Ukolova, S. V. Monakhov, J. A. Shikhanova, J. Environ. Manag. Tour. 3, 608 (2017)

5. E. A. Skvortsov, E. G. Skvortsova, I. S. Sandu, G. A. Iovlev, Econ. Reg. 3, 1021 (2018)

6. K. S. Ternovykh, V. V. Kurennaya, A. V. Agibalov, Vestnik VSAU. 2, 98 (2020)

7. I. Trunina, O. Onyshchenko, O. Vartanova, O. Sushchenko, International J. of engineering and technology, 7(4.3), 530 (2018)

8. M. L. Vartanova, E.V. Drobot. Econ. relations, 1, 12 (2018)

9. E. Yu. Vinogradova, A. V. Babkin, A. I. Galimova, S. L. Andreeva, Proceedings of 2017 SPUE, 63 (2017)

10. E. Vinogradova, O. Nikoliuk, A. Galimova. E3S Web of Conferences, 208 (2020) 